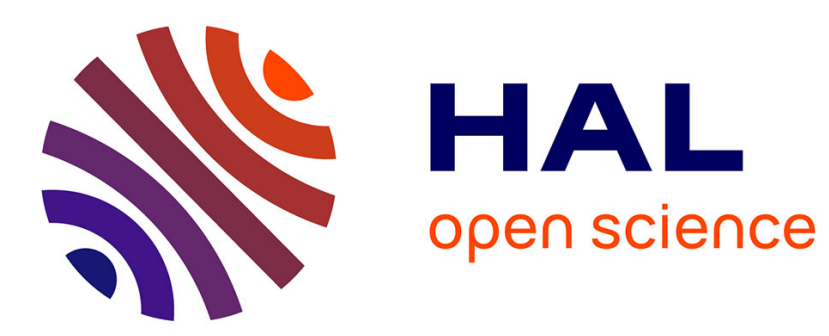

\title{
Structure of $\mathrm{TiO} 2(011)$ revealed by photoelectron diffraction
}

\author{
Céline Dupont, S. Bourgeois, P. Le Fèvre, A. Verdini, L Floreano, B.
}

Domenichini

\section{To cite this version:}

Céline Dupont, S. Bourgeois, P. Le Fèvre, A. Verdini, L Floreano, et al.. Structure of TiO 2 (011) revealed by photoelectron diffraction. Physical Review B, 2016, 94 (24), 10.1103/PhysRevB.94.241304 . hal-03032735

\section{HAL Id: hal-03032735 \\ https://hal.science/hal-03032735}

Submitted on 1 Dec 2020

HAL is a multi-disciplinary open access archive for the deposit and dissemination of scientific research documents, whether they are published or not. The documents may come from teaching and research institutions in France or abroad, or from public or private research centers.
L'archive ouverte pluridisciplinaire HAL, est destinée au dépôt et à la diffusion de documents scientifiques de niveau recherche, publiés ou non, émanant des établissements d'enseignement et de recherche français ou étrangers, des laboratoires publics ou privés. 


\title{
The structure of $\mathrm{TiO}_{2}(011)$ revealed by photoelectron diffraction.
}

\author{
C. Dupont,${ }^{1, *}$ S. Bourgeois,${ }^{1}$ P. Le Fèvre, ${ }^{2}$ A. Verdini,${ }^{3}$ L. Floreano,${ }^{3}$ and B. Domenichini ${ }^{1}$ \\ ${ }^{1}$ Laboratoire Interdisciplinaire Carnot de Bourgogne (ICB), \\ UMR 6303 CNRS, Univ. Bourgogne Franche-Comté, \\ BP 47870, 21078 Dijon Cedex, France \\ ${ }^{2}$ Synchrotron SOLEIL, L'Orme des Merisiers, \\ BP 48, 91192 Gif-sur-Yvette, France \\ ${ }^{3}$ Istituto Officina dei Materiali IOM-CNR, \\ Laboratorio TASC s.s. $14 \mathrm{~km}$ 163.5, 34149 Trieste (Italy)
}

(Dated: December 7, 2016)

\begin{abstract}
The combination of photoelectron diffraction, density functional theory and multiple scattering calculations is used for a quantitative analysis of the widely debated structure of $\mathrm{TiO}_{2}(011)$. The modeling of the diffraction patterns for different surface reconstructions allows to discriminate the key structural constraints required or, on the contrary, prohibited in the reconstruction of this termination. In particular photodiffraction rules out previously proposed reconstructions while it evidences the key feature of the $\mathrm{TiO}_{2}(011)$ termination: an oxygen splitting induced by missingrows.
\end{abstract}




\section{INTRODUCTION}

Since the discovery of the ability of $\mathrm{TiO}_{2}$ for photocatalytic applications such as water splitting $^{1}$, numerous studies have been dedicated to this material ${ }^{2-8}$. Nowadays the most stable (110) termination of the rutile form is fully characterized: its electronic and structural properties are well-known, as well as its wide range of potential applications. On the contrary, besides its potential for photocatalysis ${ }^{9,10}$ the structure of the (011) termination is still under debate. Both experimental, theoretical or even combined studies have been performed, but none of them has proposed a structure that reaches a general consensus. First investigations ${ }^{11,12}$ proposed a "titanyl" model based on surface $\mathrm{Ti}=\mathrm{O}$ groups, however this model was rapidly refuted to give way to new hypotheses. Among them one can mainly distinguish two kinds of reconstructions: the "missing-row" models, obtained by removing atoms from the surface ${ }^{13}$ (in the spirit of the "titanyl" model) and those obtained only by rearrangement of surface atoms ${ }^{14-17}$. After these thorough investigations, a convergence towards the $(2 \times 1)$ "brookite (001)-like" (BL) reconstruction (firstly proposed by Torrelles et $\left.a l .{ }^{14}\right)$ was seemingly reached, but a recent paper ${ }^{18}$ suggested the coexistence of two phases, namely the $(4 \times 1)-\alpha$ derived from the previous model of Torrelles ${ }^{14}$ and a new $(4 \times 1)-\beta$ phase. Beyond the reconstruction itself, this last paper has also raised up the question of the nature of the second layer: does the reconstruction occur on the native $(1 \times 1)$ surface or is the second layer also reconstructed? Finally Wang et al. ${ }^{19}$ have recently published a different approach for investigating the $\mathrm{TiO}_{2}(011)$ reconstruction as they considered the influence of partial pressure of oxygen, which allows them to consider non stoichiometric models. Nevertheless beyond these specific conditions, they no longer highlight only the "brookite (001)-like" model but they also consider the existence of missing row and micro faceting ones.

To dispel all uncertainties, we report an investigation combining techniques hitherto not applied to resolve the reconstruction of $\mathrm{TiO}_{2}(011)$. In this paper, the structure of the (011) stoichiometric termination is investigated through density functional theory (DFT) and multiple scattering (MS) calculations combined with PhotoElectron Diffraction (PED). Indeed, PED is an experimental technique, particularly suited for studies of surfaces, as it probes the local order around chemically selected emitters. ${ }^{20,21}$ 


\section{METHOD}

\section{A. Experimental details}

The experiments were performed at the ALOISA beamline ${ }^{22}$ of the Elettra Synchrotron Light Source in Trieste, Italy. The rutile $\mathrm{TiO}_{2}$ (011) surface was prepared using first, repeated cycles of $\mathrm{Ar}^{+}$-ion bombardments $(1 \mathrm{keV})$ and annealing at $973 \mathrm{~K}$ in order to create conductivity in material bulk via oxygen deficiencies and then removed any charge effect under photoemission process. Contrary to previous studies ${ }^{11,13,14,17,18}$ which performed the whole preparation process under UHV, our last annealing was carried under $\mathrm{O}_{2}$ (pressure of about $10^{-4} \mathrm{~Pa}$ ) at $723 \mathrm{~K}$ out for $15 \mathrm{~min}$, in order to re-oxidize the top most layers. This preparation ensures to have a stoichiometric surface and thus allows accurate comparison with calculations. The surface is then controlled by RHEED (Reflection High Energy Electron Diffraction) in order to reveal the main surface orientations and to check the degree of ordering from the spot width. In fact, the good quality of the surface is also evidenced by the high modulation of PED data (ca. 50\%, see below). Besides, we paid attention to the surface stoichiometry as monitored by the $\mathrm{Ti}^{3+} 3 \mathrm{~d}$ states just below the Fermi level, which exhibit a strong resonance behavior when the photon energy goes through the Ti L2,3 edges $^{23}$. After $\mathrm{O}_{2}$ treatment, no $\mathrm{Ti}^{3+} 3 \mathrm{~d}$ states are detectable at resonance. For PED experiments, the X-ray beam was impinging on the sample at grazing incidence $\left(4^{\circ}\right)$ with light polarization normal to the surface. Photoemission intensities were recorded as a function of polar $(\theta)$ and azimuthal $(\phi)$ angle. Photoelectron diffraction spectra were measured at room temperature for photoelectrons from the Ti2p core level with a kinetic energy of $464 \mathrm{eV}$. For the analysis we evaluate the anisotropy function $\chi(\theta, \phi)=\left[I(\theta, \phi)-I_{0}(\theta)\right] / I_{0}(\theta)$, where $I_{0}(\theta)$ is the $\phi$ average of $I(\theta, \phi)$ and represents the smoothly varying isotropic function, as originated by both instrumental details (illuminated area) and physical properties (atomic angular cross-section, escape depth, surface roughness). ${ }^{24}$ We call PED pattern the stereographic $\chi(\theta, \phi)$ plot. The difference between two patterns $\chi_{A}$ and $\chi_{B}$ can be quantified from the $R$-factor, $R_{f}=\sum\left(\chi_{A}-\chi_{B}\right)^{2} / \sum\left(\chi_{A}^{2}+\chi_{B}^{2}\right)$, where the sum is performed over the whole experimental angular ranges. In this case $\theta=0^{\circ} \rightarrow 69^{\circ}$, where $0^{\circ}$ is along the surface normal and $\phi=0^{\circ} \rightarrow 90^{\circ}$, between the two symmetry directions. $R_{f}=0$ and $R_{f}=1$ corresponds to identical and uncorrelated datasets, respectively. 


\section{B. Computational details}

In order to determine the optimal reconstruction, periodic density functional theory calculations have been performed using the VASP package ${ }^{25,26}$. All reconstructions have been modeled with symmetric slabs of eleven layers of $\mathrm{TiO}_{2}$ (corresponding to a slab thickness of $27.2 \AA$ for the native $\mathrm{TiO}_{2}(011)$ slab) reconstructed on both sides to avoid any spurious dipolar moment. The large thickness of eleven layers as been chosen to allow a high convergence of the surface reconstruction. Total energy calculations have been performed following the GGA+U approximation with the Perdew-Burke-Ernzerhof (PBE) functional ${ }^{27}$, and a value of $4.2 \mathrm{eV}$ for $\mathrm{U}$ in the Dudarev's approach ${ }^{28}$. The projector-augmented-wave (PAW) method has been used, with 12 valence electrons for Ti (namely $3 s^{2}, 3 p^{6}, 4 s^{2}$ and $3 d^{2}$ ) and 6 for $\mathrm{O}$ (namely $2 s^{2}$ and $2 p^{4}$ ) and a converged plan-wave cutoff of $500 \mathrm{eV}$ has been applied. The Brillouin zone integration has been performed with a $(3 \times 3 \times 1)$ Monkhorst-Pack k-point mesh. The geometry optimization has been completed when forces becomes smaller than $0.01 \mathrm{eV} . \AA^{-1}$. With these settings, the numerical error on the total energy is lower than $0.01 \mathrm{eV}$. Experimentally, a kinetic energy of emitted electrons of $464 \mathrm{eV}$ has been used corresponding to an inelastic mean free path of $12 \AA^{29}$, i.e. an analysis thickness spread over 15 atomic layers, namely $5 \mathrm{TiO}_{2}$ layers. Once stable structures have been obtained, the corresponding PED patterns were modeled by performing multiple scattering calculations using the EDAC code ${ }^{30}$, within the cluster approach. To allow accurate comparisons, fixed cluster of 375 atoms have been used in all cases.

\section{RESULTS}

In order to evidence the main characteristics of the (011) termination, numerous reconstructions (18), including all structures previously proposed in the literature, have been modeled. In particular, the widely reported $\mathrm{BL}^{14,15}$ has been considered, as well as the firstly proposed titanyl model ${ }^{11}$. The microfacet (MF) model proposed by Kubo et al. ${ }^{13}$ has been adapted in order to make it stoichiometric and thus has also been investigated within the two periodicities, namely $(2 \times 1)$ and a $(4 \times 1)$. In particular, to preserve the stoichiometry, $\mathrm{Ti}_{2} \mathrm{O}_{4}$ rows have been removed, instead of $\mathrm{Ti}_{2} \mathrm{O}_{2}$. Finally, in agreement with the paper of 
Pang et al. ${ }^{18}$, the $(4 \times 1) \alpha$, the $(4 \times 1) \beta$ and multilayer models have been considered. For this last case, we mainly optimized combinations of the MF and the BL model. Different arrangements have been considered depending on the first layer and second layer reconstruction (namely Layer1=MF / Layer2=MF or Layer1=MF / Layer2=BL or Layer1=BL / Layer2=MF) and through the combination of different periodicities. Their relative stability has been considered through their surface energy (see Table I) and their corresponding photoelectron diffraction patterns have been calculated.

First of all, the experimental PED data set, as well as the calculated one of the non reconstructed (011) termination are reported on Figure 1. Since the angular position of focusing peaks in PED patterns is well-known to provide short-range information on the structure of the topmost layers ${ }^{20,21}$, a few qualitative conclusions can be drawn from the visual comparison of the patterns. Especially, we notice a remarkable agreement between the main diffraction features and the calculated ones for a non reconstructed termination. Nevertheless some discrepancies become evident upon quantitative analysis. Among them, one can mention the case of features A and B. Experimentally they present an identical intensity, while on the calculated PED spectrum of native (011), B feature is of very low intensity compared to $\mathrm{A}$. This is also the case of $\mathrm{C}$ feature, which presents a much lower intensity in the calculated patterns. On the contrary, the central $\mathrm{G}$ feature is more pronounced on the calculated pattern rather than on the experimental one. Finally one can observe the additional $\mathrm{F}$ point as well as a spurious mark below the I feature, on the calculated anisotropy pattern of the non reconstructed surface.

From our calculations the titanyl model ${ }^{11,12}$ can be immediately excluded. Its PED pattern (see Figure 2-(c)) leads to a large $R_{f}$ of 0.81 . This is mainly due to the large central spot, which encompasses both $\mathrm{A}$ and $\mathrm{B}$ diffraction points and almost extends to the $\mathrm{D}$ feature. Other imprecisions can be mentioned, like the $\mathrm{E}$ feature presenting a too large value of $\phi$ and the large intensity of the $\mathrm{G}$ feature. This really poor agreement confirms previous studies ${ }^{13,14}$ which have already dismissed this model. A second unsuitable model is the $(4 \times 1)-\beta$ recently proposed by Pang et al. ${ }^{18}$. The structure as reported in ${ }^{18}$ is non stoichiometric, hence several attempts have been performed to reproduce similar reconstruction patterns in a stoichiometric configuration. The most stable case leads to a calculated surface energy of 125 meV.A ${ }^{-2}$ (see Table I), namely $25 \%$ less stable than the native termination. This large surface energy is heightened by a high $R_{f}$ of 0.77 due to a large $G$ spot and 


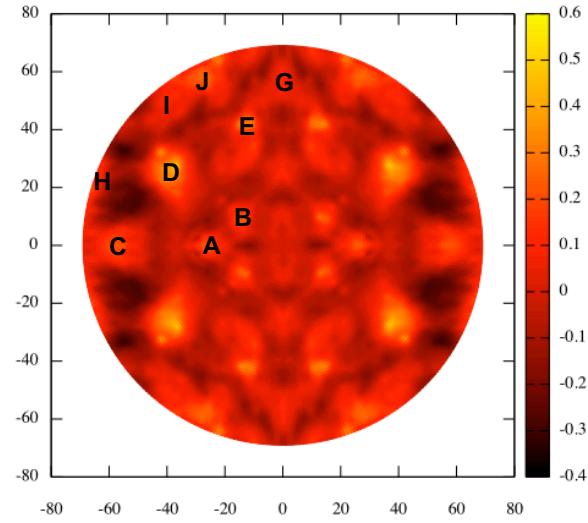

(a)

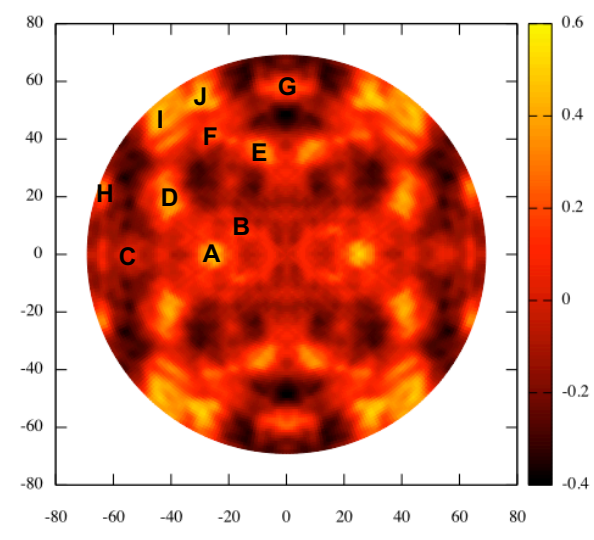

(b)

Figure 1. (a) Experimental photoelectron diffraction (PED) pattern $\chi(\theta, \phi)$, from the Ti2p core level. Main diffraction points are denoted from A to G. (b) Calculated photoelectron diffraction pattern for the non reconstructed $\mathrm{TiO}_{2}(011)$ termination (Corresponding structure is reported on Figure S1 of supplementary information). The projection is linear in $\theta$ with the surface normal $(\theta=0)$ in the center. $\phi=0(\phi=90)$ is found a 3 o'clock (12 o'clock) and corresponds to the [100] $([0-\overline{1}-\overline{1}])$ direction.

\begin{tabular}{l|c|c}
\hline \hline Model & Surface energy $\left(\mathrm{meV} / \mathrm{A}^{2}\right)$ & $\mathrm{R}_{f}$ \\
\hline BL model (Fig2 -(c) $)^{14,15,17}$ & 92 & 0.78 \\
Native (011) (Fig1 - (b)) & 99 & 0.66 \\
Multilayer: MF / BL & 104 & 0.79 \\
Titanyl model ${ }^{11,12}$ & 109 & 0.81 \\
MF - $4 \times 1$ (Fig2 -(b)) Adapted from & \\
Multilayer: MF / MF & 110 & 0.57 \\
MF - $2 \times 1$ Adapted from ${ }^{13}$ & 110 & 0.63 \\
$4 \times 1-\alpha$ model $^{18}$ & 113 & 0.67 \\
Multilayer: BL / MF & 119 & 0.74 \\
$4 \times 1-\beta$ model $^{18}$ & 119 & 0.86 \\
\hline \hline
\end{tabular}

Table I. Surface energy in $\mathrm{meV} / \mathrm{A}^{2}$ and reliability factor for different models for the rutile (011) termination. MF stands for MicroFacet, while BL stands for Brookite like. 
features B, D, E and J being almost non existent (see Figure 2-(e)). The same conclusions can be drawn for the $(4 \times 1)-\alpha$ still proposed by Pang et al. ${ }^{18}$. In fact, this model is just slightly more stable than the $(4 \times 1)-\beta$, with a surface energy of $119 \mathrm{meV} . \mathrm{A}^{-2}$, but it also presents a high $\mathrm{R}_{f}$ of 0.74 , with a similar flat appearance of the PED pattern (see Figure $2-(\mathrm{d}))$.

Based on these first conclusions, we focus on the BL model proposed by the group of Thornton $^{14}$ and the one of Diebold ${ }^{15}$ and on the stoichiometric microfacet one developed here by adapting the model of the group of Nozoye ${ }^{13}$ et al.. Given the pretty low differences of surface energies between these different reconstructions, all included in a $10 \%$ range around the surface energy of the native termination (see Table I), the only consideration of the stability is not sufficient to discriminate a model among the others. Hence we will mainly discuss PED patterns and the corresponding reliability factors.

According to Table I, all reconstructions, except those derived from the MF model, present a reliability factor higher than the one of the native termination. In particular this is the case of the widely accepted BL model, with $R_{f}=0.78$. Beyond this low quantitative agreement, qualitatively the PED spectra of the BL model presents two major defects: the $\mathrm{B}$ feature is missing, while the $\mathrm{G}$ feature is far too much intense (see Figure 2-(f)). This large intensity is due to the combination of two phenomena. In fact, $G$ is already present in the native termination, where it can be attributed to the scattering between two titanium atoms in two standard rutile layers. Apart from rearrangement of the surface layer, the BL model is constituted of standard rutile layers which contribute to G. Besides this titanium-titanium diffraction, the specific rearrangement of the BL model leads to a Ti-O diffraction from a titanium atom of the relaxed layer. This surface diffraction certainly yields the main contribution to $\mathrm{G}$.

Following this analysis based on the $R_{f}$, the stoichiometric MF model with the $(4 \times 1)$ periodicity appears to be the best model for the $\mathrm{TiO}_{2}(011)$ termination. This is confirmed by the qualitative appearance of the PED spectra reported on Figure 2-(b). Hence the main weaknesses of the non reconstructed termination and of the BL model simulations are improved: the B feature appears with a more pronounced intensity, as well as the $\mathrm{C}$ feature, whereas the intensity of $\mathrm{G}$ is reduced. All these changes can be explained thanks to the specific multifacet reconstruction reported on Figure 3 while its main geometric characteristics 


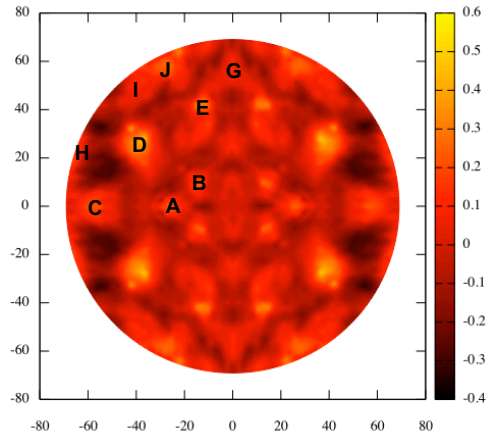

(a)

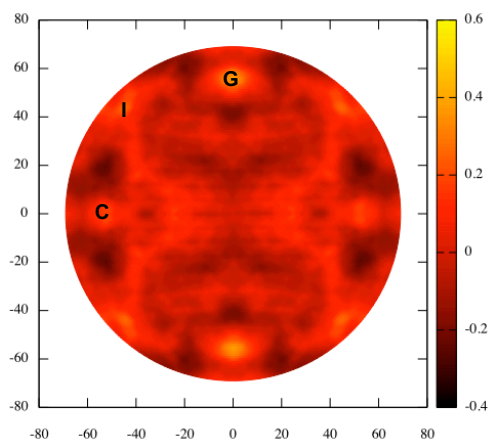

(d)

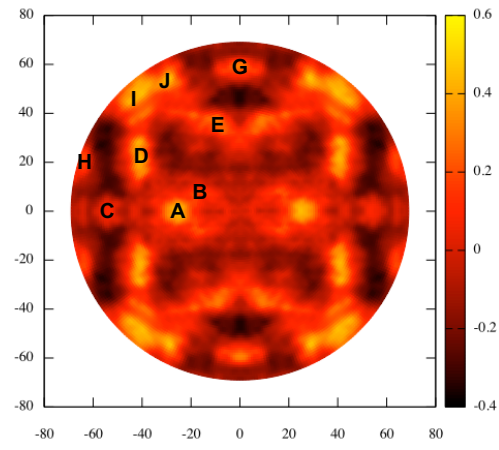

(b)

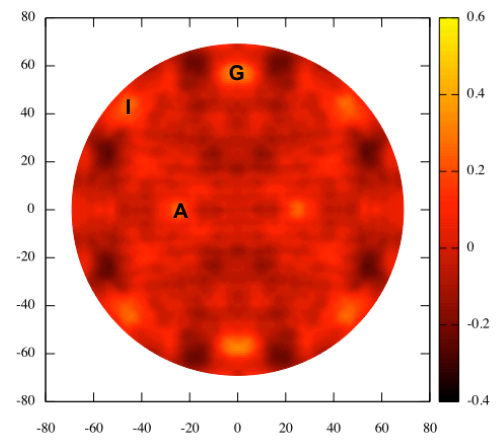

(e)

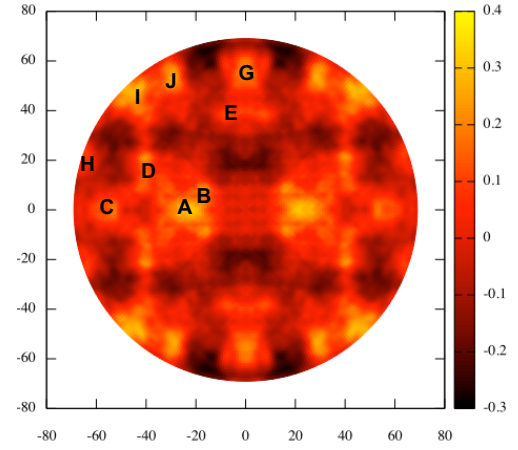

(c)

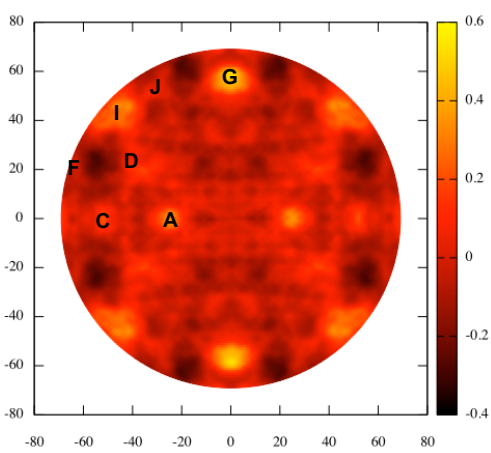

(f)

Figure 2. (a) Experimental photoelectron diffraction (PED) patterns $\chi(\theta, \phi)$, from the Ti2p core level. Calculated photoelectron diffraction patterns for $(b)$ the stoichiometric microfacet $(4 \times 1)$ reconstruction, (c) the titanyl model, (d) the $(4 \times 1)-\alpha$ from $^{18},(\mathrm{e})(4 \times 1)-\beta$ from $^{18}$ and for (f) the "brookite (001)-like" model. Main diffraction points are denoted from A to G. Corresponding structures for (c), (d), (e) and (f) are reported on Figure S2, S3, S4, S5 of supplementary information, respectively.

are detailed in Table II. Hence, the key feature which explains the low $R_{f}$ is the presence of point B. This contribution is specific to this reconstruction and can be seen as a split of feature A. In fact, A is due to Ti-O scattering from titanium atoms of the second layer on oxygen atoms of the sublayer, like $\mathrm{Ti}_{11}-\mathrm{O}_{9}, \mathrm{Ti}_{12}-\mathrm{O}_{10}, \mathrm{Ti}_{13}-\mathrm{O}_{11}$ and $\mathrm{Ti}_{14}-\mathrm{O}_{12}$ (see Figure 3 ). $\mathrm{B}$ also comes from the same kind of Ti-O diffraction, but related to atoms at the edge of the reconstruction, namely $\mathrm{Ti}_{7}-\mathrm{O}_{7}$ and $\mathrm{Ti}_{10}-\mathrm{O}_{8}$. In fact, while in non reconstructed areas oxygen atoms of the sublayer stands right above titanium atoms of the second layer within the same

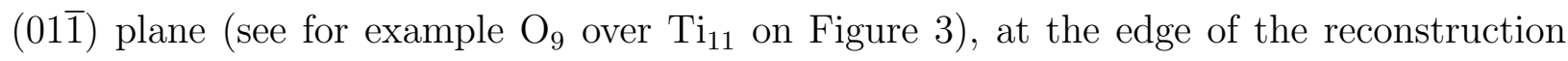
a slight transverse shift of the oxygen atom can be observed. This is clearly evidenced by 

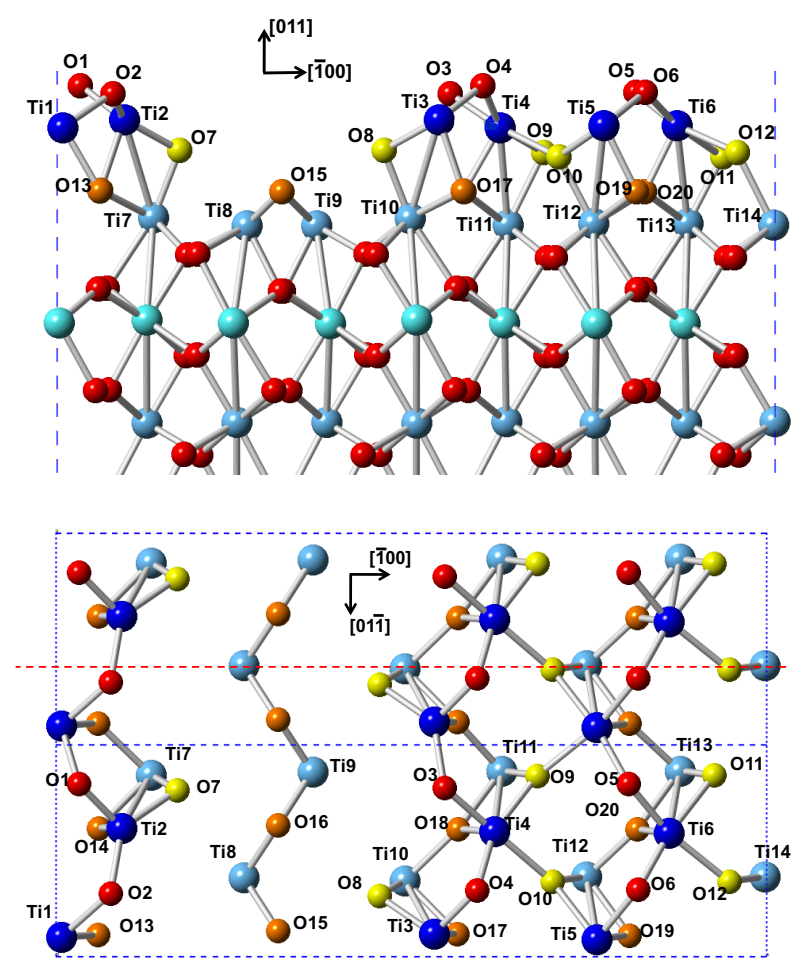

Figure 3. (TOP) Side view and (BOTTOM) Top view of the stoichiometric MicroFacet reconstruction. Titanium atoms are reported in different shades of blue, while oxygen atoms are in red, yellow and orange, depending on their layer. Main atoms are numbered. Blue dashed lines represent the cell used for DFT calculations, defined with the following parameters: $a=18.372 \AA, b=5.463 \AA$, $\mathrm{c}=45.000 \AA$.

the red dotted line on the bottom part of Figure 3. While $\mathrm{O}_{10}$ and $\mathrm{O}_{12}$ (resp. $\mathrm{O}_{9}$ and $\mathrm{O}_{11}$ ) are perfectly lined up with $\mathrm{Ti}_{8}, \mathrm{Ti}_{10}, \mathrm{Ti}_{12}$ and $\mathrm{Ti}_{14}$ (resp. $\mathrm{Ti}_{7}, \mathrm{Ti}_{9}, \mathrm{Ti}_{11}$ and $\left.\mathrm{Ti}_{13}\right), \mathrm{O}_{8}$ (resp. $\left.\mathrm{O}_{7}\right)$ is moved away from $\mathrm{Ti}_{10}\left(\right.$ resp. $\left.\mathrm{Ti}_{7}\right)$. This is also traduced by the decrease of the $T i-\widehat{T i}-O$ angle, from $43^{\circ}$ for $T i_{6}-\widehat{T i_{13}}-O_{11}$ to $38^{\circ}$ for $T i_{2}-\widehat{T i_{7}}-O_{7}$. A second benefit of this reconstruction is to increase the intensity of feature C. Likewise A and B, it comes from a Ti-O diffraction from second titanium layer to oxygen sublayer but now with a gap between titanium and oxygen. Among others, $\mathrm{C}$ is due to the following scattering paths: $\mathrm{Ti}_{7}-\mathrm{O}_{11}, \mathrm{Ti}_{8}-\mathrm{O}_{8}, \mathrm{Ti}_{9}-\mathrm{O}_{9}, \mathrm{Ti}_{11}-\mathrm{O}_{11}, \mathrm{Ti}_{13}-\mathrm{O}_{7}, \ldots$ Hence, the presence of the missing row induces an increase of the intensity of scattering from oxygen atoms protruding over the troughs, like $\mathrm{O}_{7}$ and $\mathrm{O}_{8}$. Finally we evidenced that the MF $(4 \times 1)$ model allows to decrease the intensity of $\mathrm{G}$ feature. As mentioned previously in the case of the BL model, G is due 


\begin{tabular}{|c|c|c|c|c|c|}
\hline Bond & $\mathrm{d}(\AA)$ & Bond & $\mathrm{d}(\AA)$ & Angle & $\left({ }^{\circ}\right)$ \\
\hline $\mathrm{Ti}_{1}-\mathrm{O}_{1}$ & 1.90 & $\mathrm{Ti}_{8}-\mathrm{O}_{15}$ & 1.87 & $\mathrm{Ti}_{1}-\mathrm{O}_{1}-\mathrm{Ti}_{2}$ & 111 \\
\hline $\mathrm{Ti}_{1}-\mathrm{O}_{2}$ & 1.91 & $\mathrm{Ti}_{8}-\mathrm{O}_{16}$ & 1.84 & $\mathrm{Ti}_{1}-\mathrm{O}_{2}-\mathrm{Ti}_{2}$ & 119 \\
\hline $\mathrm{Ti}_{2}-\mathrm{O}_{1}$ & 1.82 & $\mathrm{Ti}_{9}-\mathrm{O}_{15}$ & 1.84 & $\mathrm{Ti}_{3}-\mathrm{O}_{3}-\mathrm{Ti}_{4}$ & 119 \\
\hline $\mathrm{Ti}_{2}-\mathrm{O}_{2}$ & 1.84 & $\mathrm{Ti}_{9}-\mathrm{O}_{15}$ & 1.84 & $\mathrm{Ti}_{3}-\mathrm{O}_{4}-\mathrm{Ti}_{4}$ & 111 \\
\hline $\mathrm{Ti}_{3}-\mathrm{O}_{3}$ & 1.84 & $\mathrm{Ti}_{9}-\mathrm{O}_{16}$ & 1.87 & $\mathrm{Ti}_{5}-\mathrm{O}_{5}-\mathrm{Ti}_{6}$ & 124 \\
\hline $\mathrm{Ti}_{3}-\mathrm{O}_{4}$ & 1.82 & $\mathrm{Ti}_{10}-\mathrm{O}_{8}$ & 1.90 & $\mathrm{Ti}_{5}-\mathrm{O}_{6}-\mathrm{Ti}_{6}$ & 124 \\
\hline $\mathrm{Ti}_{4}-\mathrm{O}_{3}$ & 1.91 & $\mathrm{Ti}_{10}-\mathrm{O}_{17}$ & 2.05 & $\mathrm{Ti}_{7}-\mathrm{O}_{13}-\mathrm{Ti}_{14}$ & 134 \\
\hline $\mathrm{Ti}_{4}-\mathrm{O}_{4}$ & 1.90 & $\mathrm{Ti}_{10}-\mathrm{O}_{18}$ & 2.03 & $\mathrm{Ti}_{7}-\mathrm{O}_{14}-\mathrm{Ti}_{14}$ & 132 \\
\hline $\mathrm{Ti}_{5}-\mathrm{O}_{5}$ & 1.87 & $\mathrm{Ti}_{11}-\mathrm{O}_{9}$ & 2.08 & $\mathrm{Ti}_{8}-\mathrm{O}_{15}-\mathrm{Ti}_{9}$ & 123 \\
\hline $\mathrm{Ti}_{5}-\mathrm{O}_{6}$ & 1.87 & $\mathrm{Ti}_{11}-\mathrm{O}_{17}$ & 1.92 & $\mathrm{Ti}_{8}-\mathrm{O}_{16}-\mathrm{Ti}_{9}$ & 123 \\
\hline $\mathrm{Ti}_{6}-\mathrm{O}_{5}$ & 1.87 & $\mathrm{Ti}_{11}-\mathrm{O}_{18}$ & 2.07 & $\mathrm{Ti}_{10}-\mathrm{O}_{17}-\mathrm{Ti}_{11}$ & 132 \\
\hline $\mathrm{Ti}_{6}-\mathrm{O}_{6}$ & 1.87 & $\mathrm{Ti}_{12}-\mathrm{O}_{10}$ & 1.93 & $\mathrm{Ti}_{10}-\mathrm{O}_{18}-\mathrm{Ti}_{11}$ & 135 \\
\hline $\mathrm{Ti}_{7}-\mathrm{O}_{7}$ & 1.90 & $\mathrm{Ti}_{12}-\mathrm{O}_{19}$ & 2.04 & $\mathrm{Ti}_{12}-\mathrm{O}_{19}-\mathrm{Ti}_{13}$ & 131 \\
\hline $\mathrm{Ti}_{7}-\mathrm{O}_{13}$ & 2.03 & $\mathrm{Ti}_{12}-\mathrm{O}_{20}$ & 1.96 & $\mathrm{Ti}_{12}-\mathrm{O}_{20}-\mathrm{Ti}_{13}$ & 131 \\
\hline $\mathrm{Ti}_{7}-\mathrm{O}_{14}$ & 2.06 & $\mathrm{Ti}_{13}-\mathrm{O}_{11}$ & 1.93 & $\mathrm{Ti}_{2}-\mathrm{Ti}_{7}-\mathrm{O}_{7}$ & 38 \\
\hline $\mathrm{Ti}_{14}-\mathrm{O}_{12}$ & 2.08 & $\mathrm{Ti}_{13}-\mathrm{O}_{19}$ & 1.96 & $\mathrm{Ti}_{6}-\mathrm{Ti}_{13}-\mathrm{O}_{11}$ & 43 \\
\hline $\mathrm{Ti}_{14}-\mathrm{O}_{13}$ & 2.07 & $\mathrm{Ti}_{13}-\mathrm{O}_{20}$ & 2.04 & & \\
\hline $\mathrm{Ti}_{14}-\mathrm{O}_{14}$ & 1.92 & $\mathrm{Ti}_{13}-\mathrm{O}_{20}$ & 2.04 & & \\
\hline
\end{tabular}

Table II. Values for main distances (in $\AA$ ) and angles $\left(\right.$ in $^{\circ}$ ). Numbering of atoms refers to Figure 3.

to a Ti-Ti diffraction between two standard rutile layers, like for example $\mathrm{Ti}_{11}$ - $\mathrm{Ti}_{4}$. In the case of our MF model, the missing row removes two diffraction channels, those due to $\mathrm{Ti}_{8}$ and $\mathrm{Ti}_{9}$, inducing the decrease of intensity for the $\mathrm{G}$ feature.

In agreement with the study of Kubo et $a l .{ }^{13}$, we have also considered the MF model with a $(2 \times 1)$ periodicity. Like for the $(4 \times 1) \mathrm{MF}$ model fully described above, we removed $\mathrm{TiO}_{2}$ rows, but one out of two instead of one out of four. According to Table I, this leads to a increase of $R_{f}$ from 0.57 to 0.67 , a value similar to those of the non native $\mathrm{TiO}_{2}(011)$ termination. This is directly related to the B feature. In fact with this high density of missing 
rows, the transverse shift of edge oxygen atoms is no longer observed and all sublayer oxygen atoms remain within the $(01 \overline{1})$ plane of the corresponding titanium atom underneath.

Finally the case of multilayer model, namely when the reconstruction occurs over an already reconstructed platform, is discussed, according to the recent paper of Pang et al. ${ }^{18}$. As mentioned above, different combinations of our MF model and the BL one have been considered. From the results reported in Table I one can conclude that the presence of a second layer already reconstructed does not lead to drastic changes, neither for the surface energy, nor for the reliability factor. Multilayer can be seen as an average of the models from which they derive. Hence the presence of these multilayer models does not introduce any new geometrical characteristic and thus no new diffraction patterns. If they are experimentally observed, this might be explained as related to a residual roughness after surface preparation, rather than to a real physical stability. To evaluate the presence or not of these multilayer models in our specific case, we perform a quantitative analysis through the reliability factor $\left(\mathrm{R}_{f}\right)$. More precisely we combine several reconstruction models and determine which weight of each model leads to the lowest $\mathrm{R}_{f}$. This careful analysis does not lead to any significant improvement, as only a small decrease of $\mathrm{R}_{f}$ from 0.57 for the $(4 \times 1) \mathrm{MF}$ to 0.56 is observed when we introduce a contribution of $14 \%$ of the multilayer MF/MF model.

\section{CONCLUSION}

In summary, this structural investigation with a chemically selective technique such as PED brings to a deeper understanding of the rutile (011) surface reconstruction. In particular the widely discussed "brookite (001)-like" model is rejected given its divergence, both quantitatively and qualitatively, with the experimental PED spectra. On the contrary we demonstrate that our stoichiometric adaptation of the previously proposed microfacet model

is the only reconstruction able to explain the specific A/B splitting feature observed on the experimental PED spectra. The unique shift of oxygen atoms at the edge of missing row is responsible for the presence of the B feature. Thanks to photoelectron diffraction it is now proved that the $\mathrm{TiO}_{2}(011)$ termination is composed of missing rows, explained by a microfaceting model. 


\section{ACKNOWLEDGMENTS}

Calculations were performed using HPC resources from DSI-CCUB (Université de Bourgogne) and IDRIS (CNRS-Paris) resources.

* celine.dupont@u-bourgogne.fr

1 A. Fujishima and K. Honda, Nature 37, 238 (1972).

2 D. A. Tryk, A. Fujishima, and K. Honda, Electrochim. Acta 45, 2363 (2000).

3 J. H. Park, S. Kim, and A. J. Bard, Nano Lett. 6, 24 (2006).

4 M. Matsuoka, M. Kitano, M. Takeuchi, K. Tsujimaru, M. Anpo, and J. M. Thomas, Catal. Tod. 122, 51 (2007).

5 A. Fujishima, X. Zhang, and D. A. Tryk, Surf. Sci. Rep. 63, 515 (2008).

6 J. Gong, Y. Lai, and C. Lin, Electrochim. Acta 55, 4776 (2010).

7 X. Chen, S. Shen, L. Guo, and S. S. Mao, Chem. Rev. 110, 6503 (2010).

8 M. A. Henderson, Surf. Sci. Rep. 66, 185 (2011).

9 T. Ohno, K. Sarukawa, and M. Matsumura, New J. Chem. 26, 1167 (2002).

10 J. Tao, T. Luttrell, and M. Batzill, Nat. Chem. 3, 296 (2011).

11 T. J. Beck, A. Klust, M. Batzill, U. Diebold, C. D. Valentin, and A. Selloni, Phys. Rev. Lett. 93, 036104 (2004).

12 O. Dulub, C. D. Valentin, A. Selloni, and U. Diebold, Surf. Sci. 600, 4407 (2006).

13 T. Kubo, H. Orita, and H. Nozoye, J. Am. Chem. Soc. 129, 10474 (2007).

14 X. Torrelles, G. Cabailh, R. Lindsay, O. Bikondoa, J. Roy, J. Zegenhagen, G. Teobaldi, W. A. Hofer, and G. Thornton, Phys. Rev. Lett. 101, 185501 (2008).

15 X. Gong, N. Khorshidi, A. Stierle, V. Vonk, C. Ellinger, H. Dosh, H. Cheng, A. Selloni, Y. He, O. Dulub, and U. Diebold, Surf. Sci. 603, 138 (2009).

16 S. E. Chamberlin, C. J. Hirschmugl, H. C. Poon, and D. K. Saldin, Surf. Sci. 603, 3367 (2009).

17 T. Woolcot, G. Teobaldi, C. L. Pang, N. S. Beglitis, A. J. Fisher, W. A. Hofer, and G. Thornton, Phys. Rev. Lett. 109, 156105 (2012).

18 C. L. Pang, A. Yurtsever, J. Onoda, Y. Sugimoto, and G. Thornton, J. Phys. Chem. C 118, $23168(2014)$. 
19 Q. Wang, A. Oganov, O. Feya, Q. Zhu, and D. Ma, Phys. Chem. Chem. Phys. 18, 19549 (2016).

20 C. Westphal, Surf. Sci. Rep. 50, 1 (2003).

21 C. Fadley, The study of surface structures by PhotoElectron Diffraction and Auger Electron Diffraction in synchrotron radiation research: Advances in Surface and Interface Science. 1, R. Z. Bachrach, Plenum, New York (1992).

22 L. Floreano, G. Naletto, D. Cvetko, R. Gotter, N. Malvezzi, L. Marassi, A. Morgante, A. Santaniello, A. Verdini, F. Tommasini, and G. Tondello, Rev. Sci. Instr. 70, 3855 (1999).

23 P. L. Fèvre, J. Danger, H. Magnan, D. Chandesris, J. Jupille, S. Bourgeois, M. A. Arrio, R. Gotter, A. Verdini, and A. Morgante, Phys. Rev. B 69, 155421 (2004).

24 F. Bruno, L. Floreano, A. Verdini, D. Cvetko, R. Gotter, A. Morgante, M. Canepa, and S. Terreni, J. Electron. Spectrosc. Relat. Phenom. 127, 85 (2002).

25 G. Kresse and J. Hafner, Phys. Rev. B 47, 558 (1993).

26 G. Kresse and J. Furthmüller, Phys. Rev. B 54, 11169 (1996).

27 J. P. Perdew, K. Burke, and M. Ernzerhof, Phys. Rev. Lett. 77, 3965 (1996).

28 S. L. Dudarev, G. A. Botton, S. Y. Savrasov, C. J. Humphreys, and A. P. Sutton, Phys. Rev. B 57, 1505 (1998).

29 S. Tanuma, C. J. Powell, and D. R. Penn., Surf. Interf. Anal. 21, 165 (1993).

30 F. J. G. de Abajo, M. A. Van Hove, and C. S. Fadley, Phys. Rev. B 63, 075404 (2001). 